\title{
Expansion of T regulatory Cells in Lepromatous Leprosy is Mediated by Phenolic Glycolipid-1
}

\author{
Bhavyata Dua1, Bhawna Sharma ${ }^{1}$, Joy Kumar Chakma', Mamta Arora1, Rekha Bhadauria², Dipendra Kumar Mitra ${ }^{3}$ and Beenu Joshi* \\ ${ }^{1}$ National JALMA Institute for Leprosy and Other Mycobacterial Diseases (ICMR), Agra, India \\ ${ }^{2}$ School of Studies in Botany, Jiwaji University, Gwalior, India
}

${ }^{3}$ All India Institute of Medical Sciences (ICMR), New Delhi, India

\begin{abstract}
In leprosy, lepromatous form of the disease is more severe and results from suppression of $\mathrm{T}$ cell response. $T$ regulatory cells which suppress $T$ cell response has been found in higher frequency in blood and at the site of infection in leprosy. Therefore, present study was carried out to evaluate the role of Mycobacterium leprae antigens whole cell sonicate (WCS) and especially phenolic glycolipid-1 (PGL-1), which is known for its suppressive nature, in the induction of $T$ regulatory cells expansion in peripheral blood of leprosy patients. For this purpose peripheral blood mononuclear cells (PBMCs) of different category of leprosy patients and healthy controls were stimulated with $M$. leprae antigens in vitro and percentage of T regulatory cells was determined by flow cytometry. We found higher frequency of T regulatory cells in PBMCs of untreated borderline lepromatous/lepromatous leprosy (BL/LL) patients. Further, PBMCs of untreated BL/LL patients also showed higher percentage of T regs after stimulation with PGL-1. Antigen mediated expansion of T regulatory cells was also supported by results of Carboxy fluorescein succinimidyl ester (CFSE) proliferation assay. None of the antigen induced $T$ regs expansion in healthy controls, untreated tuberculoid/borderline tuberculoid (TT/BT) leprosy patients and treated leprosy patients. Therefore it is suggested that increased frequency of $T$ regs in BL/LL patients may be due to the induction of $T$ regs expansion mediated by PGL-1 of $M$. leprae and this high percentage of T regs resulted in T cell suppression in lepromatous disease.
\end{abstract}

Keywords: T regulatory cells; PGL-1; Lepromatous leprosy; T cell suppression

Abbreviations: BL: Borderline Lepromatous Leprosy; BT: Borderline
Tuberculoid Leprosy; CFSE: Carboxy Fluorescein Succinimidyl Ester;
LL: Lepromatous Leprosy; M. leprae: Mycobacterium leprae; PBMCs:
Peripheral Blood Mononuclear Cells; PGL-1: Phenolic Glycolipid-1, T
regs: T Regulatory Cells: TT: Tuberculoid Leprosy; WCS: Whole Cell
Sonicate

\section{Introduction}

Leprosy is a chronic infectious disease caused by an intracellular obligate organism Mycobacterium leprae ( $M$. leprae) that affects mainly nerves, skin and mucous membrane. It is well known that immune response of the host determines the outcome of clinical manifestation of the disease. At tuberculoid (TT) pole patients develop strong delayed type of immune response and limit the growth of the bacteria while lepromatous (LL) pole cellular immune response of the patients selectively fails to respond to the antigens of M. leprae which results in uncontrolled bacterial growth. Between these polar forms borderline tuberculoid (BT), borderline borderline (BB) and borderline lepromatous (BL) forms also occur [1-2].

$\mathrm{T}$ lymphocytes play crucial role in directing cell mediated immune response to intracellular pathogens. A recently discovered subpopulation of $\mathrm{T}$ cells which is $\mathrm{CD} 4+\mathrm{CD} 25+$ (IL-2 receptor $\beta$ chain) regulatory $\mathrm{T}$ cell expressing Fork head box protein (FoxP3) transcription factor play role in the suppression and regulation of immune response to self and nonself antigens. FoxP3 is a transcription factor which is not only a phenotypic marker of $\mathrm{T}$ regulatory cells but also essential for their development and function [3]. CD4+ CD25+ T regulatory cells suppress activation and proliferation of other CD4+ and CD8+ T cells [4-5]. Their suppressive function needs direct cellcell contact or release of anti-inflammatory cytokines interlukine-10 (IL-10) and transforming growth factor- $\beta$ (TGF- $\beta$ ) or both [6-
9]. Generally $\mathrm{T}$ regulatory cells need to be activated to exert their suppressive function [10].

T regulatory cells have been shown to be essential for establishing and maintaining persistent infection by Leishmania major [11]. In human tuberculosis various studies have also shown the increase number of $\mathrm{T}$ regulatory cells in blood and at site of infection during the active disease [12-14]. However, there are three reports on increased number of T regulatory cells in leprosy patients [15-17], two of them reported increased T regulatory cells in lepromatous leprosy patients and one reported increased $\mathrm{T}$ regulatory cells in tuberculoid leprosy patients. PGL-1 is $M$. leprae specific lipid which has been reported to be immunosuppressive [18] and highest rate of leprosy cases was detected in PGL-1 seropositive BCG unvaccinated contacts [19], therefore, we designed the present study to evaluate the percentage of T regulatory cells in different categories of leprosy patients and healthy controls to delineate their role in $\mathrm{T}$ cell suppression in leprosy. Further, frequency of $\mathrm{T}$ regulatory cells was detected in PBMCs after stimulation with M. leprae antigens to evaluate role of these antigens, especially PGL-1 in the induction of T regulatory cells.

\section{Materials and Methods}

\section{Study subjects}

Ten freshly diagnosed untreated TT/BT (Sex male $7 \&$ female 3,

*Corresponding author: Beenu Joshi, Scientist F, Department of Immunology, National JALMA Institute for Leprosy and Other Mycobacterial Diseases (ICMR) Tajganj, Agra-282001, India, Tel no: +91-562-2331756; Fax no: +91-562-2331755; E-mail: beenuj2002@yahoo.co.in

Received January 11, 2016; Accepted April 12, 2016; Published April 20, 2016

Citation: Dua B, Sharma B, Chakma JK, Arora M, Bhadauria R, et al. (2016) Expansion of $\mathrm{T}$ regulatory cells in lepromatous leprosy is mediated by Phenolic glycolipid-1. J Med Microb Diagn 5: 226. doi:10.4172/2161-0703.1000226

Copyright: (c) 2016 Dua B, et al. This is an open-access article distributed under the terms of the Creative Commons Attribution License, which permits unrestricted use, distribution, and reproduction in any medium, provided the original author and source are credited. 
Age 20-50yrs), BL/LL (Sex male 8 and female 2, Age 19-45yrs) patients and ten completely treated TT/BT Sex male 8 and female 2, Age 1850yrs), BL/LL (Sex male 8 and female 2, Age 20-55 yrs) patients attending OPD of National JALMA Institute for Leprosy and Other Mycobacterial Diseases (ICMR), Agra, India were enrolled in the study. Patients were characterized on the basis of clinical and skin smear examination. Treated patients had received the treatment till the reduction of clinical activity and skin smear negativity. None of fully treated patients received immunosuppressive therapy. Ten healthy (Sex male 6 and female 4, Age 20-44yrs) individuals working at the Institute were included as exposed healthy control. None of healthy individuals had history of TB or leprosy and also did not suffer from any infectious disease at the time of blood collection. Blood samples were collected after taking informed written consent and study was approved by Institutional ethics committee.

\section{Antigens}

M. leprae antigens whole cell sonicate (WCS) and Phenolic Glycolipid-1 (PGL-1) was procured from the laboratory of Dr. PJ Brennan under WHO contract no. NIH-N01-A1-25469.

\section{Peripheral blood mononuclear cells (PBMCs) isolation and stimulation with antigens}

PBMCs were isolated from heparinized blood by Ficoll-hypaque (Sigma, USA) density gradient centrifugation method [19] and suspended in RPMI (Sigma, USA) supplemented with 5\% fetal bovine serum (Sigma, USA), $100 \mathrm{U} / \mathrm{ml}$ penicillin, $100 \mathrm{ug} / \mathrm{ml}$ streptomycin and $2 \mathrm{nM}$ L-glutamine (Sigma, USA). For Carboxy fluorescein succinimidyl ester (CFSE) cell proliferation assay $1 \times 10^{6}$ cells were incubated with $5 \mu \mathrm{M}$ CFSE (Sigma, USA) in $37^{\circ} \mathrm{C}$ for $15 \mathrm{~min}$ in dark. Cells were then washed twice with $10 \%$ FBS containing RPMI. CFSE stained and unstained cells were then stimulated with whole cell sonicate $(10 \mu \mathrm{g} / \mathrm{ml})$ and phenolic glycolipid-1 (PGL-1) $(10 \mu \mathrm{g} / \mathrm{ml})$ of $M$. leprae and incubated at $37^{\circ} \mathrm{C}$ with $5 \% \mathrm{CO}_{2}$ for $24 \mathrm{hrs}$. Four hrs before the termination of incubation $2 \mu \mathrm{M}$ monensin was added to CFSE unstained cells.

\section{Flow cytometry}

After incubation, CFSE stained and unstained cells were stained for surface marker with the combination of following antibodies anti CD3 APC (BD-Biosciences, USA), anti CD4 PerCP (BD-Biosciences, USA), anti CD25 PECy7 (BD-Biosciences, USA), CD127 PE (BDBiosciences, USA) for $30 \mathrm{~min}$ in dark and then cells were fixed with $4 \%$ formaldehyde. CFSE unstained cells were permeabilized using FoxP3 buffer set (BD-Biosciences, USA) and stained with anti FoxP3 Alexa flour-488 (BD-Biosciences, USA). Stained cells were acquired in FACS Aria and data was analyzed by FACS Diva Software.

\section{Statistical analysis}

Difference between the groups was calculated by non-parametric Mann Whitney test using GraphPad Prism 3.0 software.

\section{Results}

\section{Increased frequency of $\mathrm{T}$ regulatory cells in untreated lepromatous leprosy patients}

To study the difference in $\mathrm{T}$ regulatory cells frequency among different category of untreated leprosy patients, completely treated leprosy patients and healthy controls, we studied the frequency of $\mathrm{CD} 3+\mathrm{CD} 4+\mathrm{CD} 25+\mathrm{FoxP} 3+\mathrm{T}$ regulatory cells by flowcytometry in the blood of these study subjects and percentage was determined using FACS Diva software (Figure 1). Significantly higher frequency of T regulatory cells was noted in untreated BL/LL patients as compared to untreated BT/TT patients and healthy subjects with $\mathrm{p}$ value 0.0144 and 0.0262 respectively (Figure 2). Frequency of $T$ regulatory cells in treated TT/BT and BL/LL patients did not differ significantly than healthy controls (Figure 2).

\section{Expansion of $\mathrm{T}$ regulatory cells by $M$. leprae antigens}

To determine whether the M. leprae antigens induce the expansion $T$ regulatory cells we first isolated PBMCs from the blood of untreated TT/BT and BL/LL patients, treated TT/BT and BL/LL patients and healthy controls and stimulated with WCS and PGL-1 for $24 \mathrm{hrs}$ and the frequency of $\mathrm{CD} 3+\mathrm{CD} 4+\mathrm{CD} 25+\mathrm{FoxP} 3+\mathrm{T}$ regulatory cells was detected by flow cytometry. Percentage of T regulatory cells stimulated with antigens in different study subjects was calculated by subtraction of percentage $\mathrm{CD} 3+\mathrm{CD} 4+\mathrm{CD} 25+\mathrm{FoxP} 3+\mathrm{T}$ regulatory cells without stimulation from $\mathrm{T}$ regulatory cells after stimulation and compared. WCS induced significantly higher percentage of $\mathrm{T}$ regulatory cells in untreated TT/BT patients than treated TT/BT patients $(\mathrm{p}=0.0376)$ and untreated BL/LL patients than in treated BL/LL patients $(\mathrm{p}=0.0144)$ (Figure 3a). Significantly higher percentages of $\mathrm{T}$ regulatory cells were noted after the stimulation of PBMCs with PGL-1 in untreated BL/LL patients compared with untreated TT-BT patients $(\mathrm{p}=0.0376)$ and healthy controls $(\mathrm{p}=0.0005)$ (Figure $3 \mathrm{~b}$ ). Percentage of PGL-1 induced $\mathrm{T}$ regulatory cells was also high in untreated TT/BT patients than treated TT/BT patients $(\mathrm{p}=0.0093)$ and untreated $\mathrm{BL} / \mathrm{LL}$ patients compared to treated BL/LL patients $(\mathrm{p}=0.0034)$ (Figure $3 \mathrm{~b})$.

To differentiate $\mathrm{T}$ regulatory cells from effector or memory $\mathrm{T}$ cells, regulatory $\mathrm{T}$ cells were stained for $\mathrm{CD} 127$. When FoxP $3+\mathrm{T}$ regulatory cells were gated for CD127, more than $80 \%$ cells were CD127low in each experiment (data not shown).

\section{CFSE cell proliferation assay}

To prove antigen mediated expansion of $\mathrm{T}$ regulatory cells, CFSE cell proliferation assay was performed and percentage of CFSE+CD3+CD4+CD25+CD127 low cells was determined by FACS Diva software (Figure 4). No proliferation was noted with WCS in CD3+CD4+CD25+CD127 low cells in healthy controls and untreated TT/BT and BL/LL patients (Figure 5a) whereas PGL-1 was found to proliferate $\mathrm{CD} 3+\mathrm{CD} 4+\mathrm{CD} 25+\mathrm{CD} 127$ low cells in $\mathrm{BL} / \mathrm{LL}$ patients than TT/BT patients $(\mathrm{p}=0.0376)$ and healthy controls $(\mathrm{p}=0.0034)$ (Figure $5 \mathrm{~b})$. No proliferation was noted after the stimulation with antigens in treated TT/BT and BL/LL patients (data not shown).

\section{Discussion}

When naïve CD4+ T cell recognize peptide on MHC molecules, they proliferate and differentiate in Th1/Th2 effector cells. In addition to Th1 and Th2, naïve CD4+ T cells can also differentiate in regulatory $\mathrm{T}$ cells by antigen recognition. $\mathrm{T}$ regulatory cells play role in preventing autoimmunity, but in addition to suppressing autoimmunity $\mathrm{T}$ regulatory cells also suppress immune response to infections thereby play role in the pathogenesis of various diseases. There are at least three subsets of CD4+ T regulatory cells involved in negative regulation of immune response, which include natural $\mathrm{T}$ regulatory cells (CD4+ CD25high Foxp3+)- generated in thymus, Tr1-IL-10 producing regulatory $\mathrm{T}$ cells generated in periphery and Th3 regsTGF- $\beta$ producing regulatory $\mathrm{T}$ cells generated in periphery $[20,21]$. Regulatory $\mathrm{T}$ cells suppress the activation and proliferation of other $\mathrm{CD} 4+$ and CD8+ $\mathrm{T}$ cells $[4,5]$. Increased frequency of $\mathrm{T}$ regulatory 


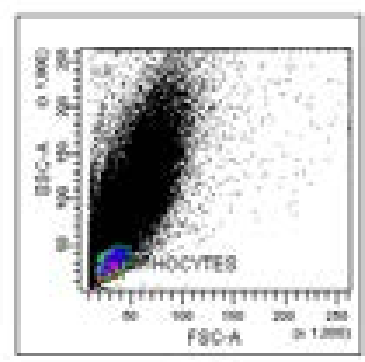

(a)

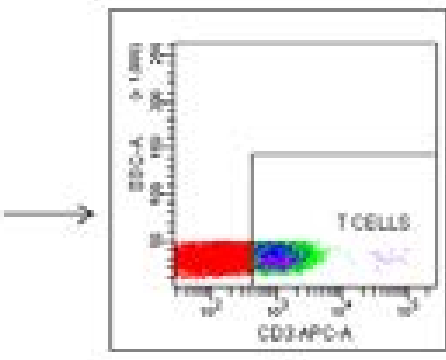

(b)

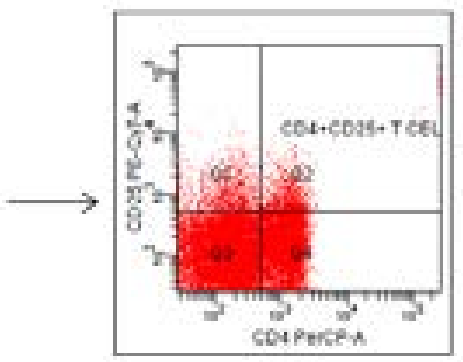

(c)

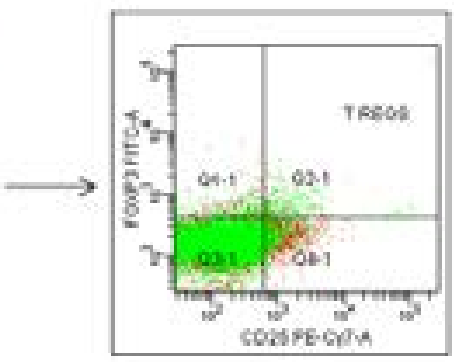

(d)

Figure 1: Representative dot plots show the gating procedure for analysis of CD3+CD4+CD25+FoxP3+ T regulatory cells. (a) Selection of lymphocyte. (b) Selection of $C D 3+$ cells from lymphocytes. (c) Selection of CD4+CD25+ cells from CD3+ cells. (d) Selection of FoxP3 + T regulatory cells from CD3+CD4+CD25+ T cells.

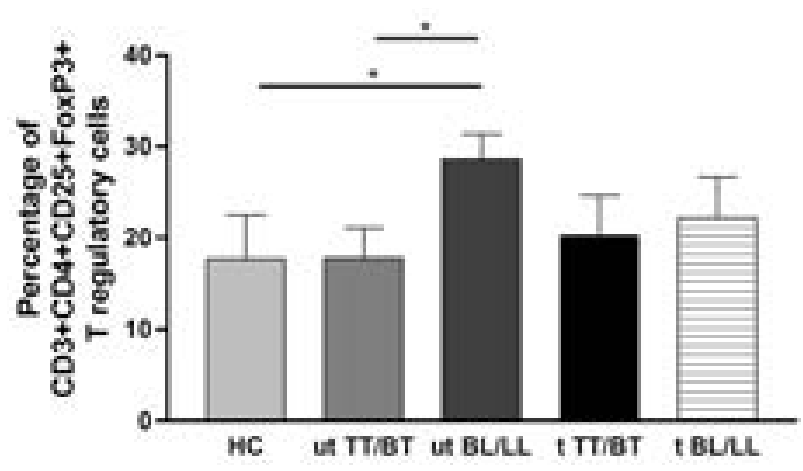

${ }^{*} \mathrm{p}<0.05$.

Figure 2: Frequency of $C D 3+C D 4+C D 25+F o x P 3+T$ regulatory cells in different study subjects [HC: healthy controls $(\mathrm{N}=10)$, ut TT/BT: untreated fresh tuberculoid leprosy patients $(\mathrm{N}=10)$, ut BL/LL: untreated fresh lepromatous leprosy patients $(\mathrm{N}=10), \mathrm{t}$ TT/BT: treated tuberculoid leprosy patients $(\mathrm{N}=10), \mathrm{t} \mathrm{BL} / \mathrm{LL}$ : treated lepromatous leprosy patients $(\mathrm{N}=10)]$.

cells has been reported in blood and site of infection of leprosy patients [15-17]. To confirm that the increased frequency of $\mathrm{T}$ regulatory cells in leprosy patients is due to the exposure of $M$. leprae or M. leprae antigens mediated expansion of $\mathrm{T}$ regulatory cells; for the first time we studied the frequency of CD3+CD4+CD25+FoxP3+ T regulatory cells in untreated and treated leprosy patients to correlate these cells with immunosuppression seen in leprosy. Further, we also evaluated the role of WCS and PGL-1 of M. leprae in induction of these cells.

On comparing the frequency of $\mathrm{CD} 3+\mathrm{CD} 4+\mathrm{CD} 25+\mathrm{FoxP} 3+\mathrm{T}$ regulatory cells, significantly higher frequency was found in blood of BL/ LL cases as compared to TT/BT cases and healthy controls in the present study. High frequency of $\mathrm{T}$ regulatory cells in lepromatous leprosy patients has also been reported by Maria et al. in 2012 [16]. A recent study has also reported increased percentage of FoxP3 $+\mathrm{T}$ regulatory cells in blood and skin biopsies of lepromatous leprosy patients [17]. In contrast to these two studies and present study higher frequency of $\mathrm{T}$ regulatory cells in blood of tuberculoid leprosy patients as compared to lepromatous leprosy patients and healthy controls has been reported by Attia et al. [15]. Our result suggests that lepromatous leprosy patients have high frequency of $\mathrm{T}$ regulatory cells in their blood and this higher frequency may be one of the factors responsible for suppression of $\mathrm{T}$ cell responses in lepromatous leprosy. To check whether this increase in the T regulatory cells frequency is due to exposure of M. leprae, effect of two M. leprae antigens WCS and PGL-1 on expansion of these cells was detected in the present study. Significantly high percentage of $\mathrm{CD} 3+\mathrm{CD} 4+\mathrm{CD} 25+\mathrm{FoxP} 3+\mathrm{T}$ regulatory cells was noted after the stimulation of PBMCs with PGL-1 in untreated BL/LL cases compared to untreated TT/BT cases and healthy controls. Increase in T regulatory cells number after exposure to M. leprae cell wall antigen (MLCwA) in lepromatous leprosy patients than in tuberculoid leprosy patients and healthy controls has been reported [16]. None of the M. leprae antigens induced the percentage of $\mathrm{T}$ regulatory cells in treated leprosy patients in our study. Furthermore, percentage of WCS and PGL-1 induced T regulatory cells was higher in untreated TT/BT patients than treated TT/BT patients and untreated BL/LL patients than in treated BL/LL patients. WCS induced percentage of T regulatory cells was higher in untreated patients than treated patients but it was not significantly higher than the percentage in healthy controls. Therefore, higher percentage of $\mathrm{T}$ regulatory cells in lepromatous leprosy could be due to the exposure of T cells to $M$. leprae PGL-1 as it induced the percentage of T regulatory cells in lepromatous leprosy patient's PBMCs than TT/ BT patients and healthy controls. Suppressive nature of PGL-1 for lymphocytes in leprosy has also been reported by Mehra et al. [18] and PGL-1 has also been reported in a study to play role in immune invasion of host by activating a complement system pathway which further leads to differentiation of IL-10 positive T regs [22]. Earlier regulatory T cell expansion by $M$. tuberculosis Mannose-capped lipoarabinomannan (ManLAM) has been reported in healthy tuberculin reactors [23]. It was shown that ManLAM induces prostaglandin E2 production which leads to $\mathrm{T}$ regulatory cells expansion. The mechanism of regulatory $\mathrm{T}$ cells induction by PGL-1 in leprosy patients has not been evaluated in our study. It is also noted in the present study that frequency of $\mathrm{T}$ regulatory cells goes down after completion of the multi-drug therapy as frequency of T regulatory cells in treated BL/LL patients was not significantly higher than healthy controls. It is also evident that this increased population of $\mathrm{T}$ regulatory cells is inducible regulatory $\mathrm{T}$ cells as the frequency increases after the exposure with M. leprae antigens.

To prove that the increased percentage of $\mathrm{T}$ regulatory cells after stimulation is due to antigen mediated proliferation, we also performed CFSE experiment to detect cell proliferation in response to $M$. leprae antigens. CD3+CD4+CD25+CD127low T cells were found to proliferate in response to PGL-1 in untreated BL/LL patients than in TT/BT patients and healthy controls. Proliferation of these cells was not detected in cells from treated TT/BT and BL/LL patients. The results of CFSE proliferation experiments support the result of antigen mediated expansion of $\mathrm{T}$ regulatory cells.

Untreated lepromatous leprosy patients have high frequency of $\mathrm{T}$ regulatory cells, and $M$. leprae antigen PGL-1 induces the percentage 
Citation: Dua B, Sharma B, Chakma JK, Arora M, Bhadauria R, et al. (2016) Expansion of T regulatory cells in lepromatous leprosy is mediated by Phenolic glycolipid-1. J Med Microb Diagn 5: 226. doi:10.4172/2161-0703.1000226

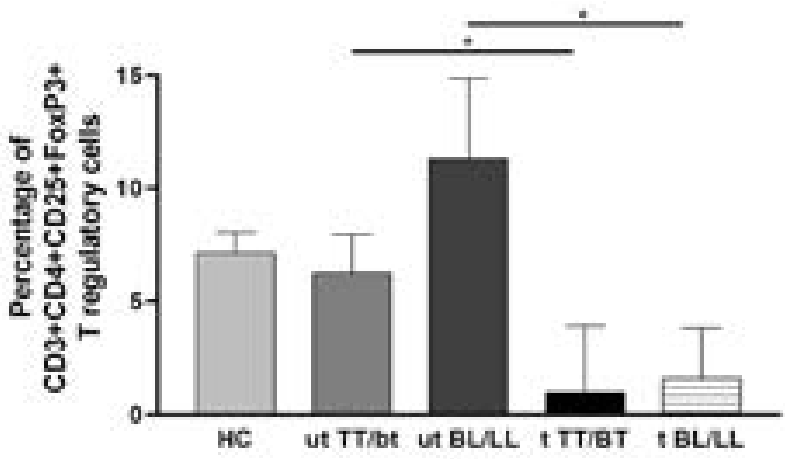

(a)

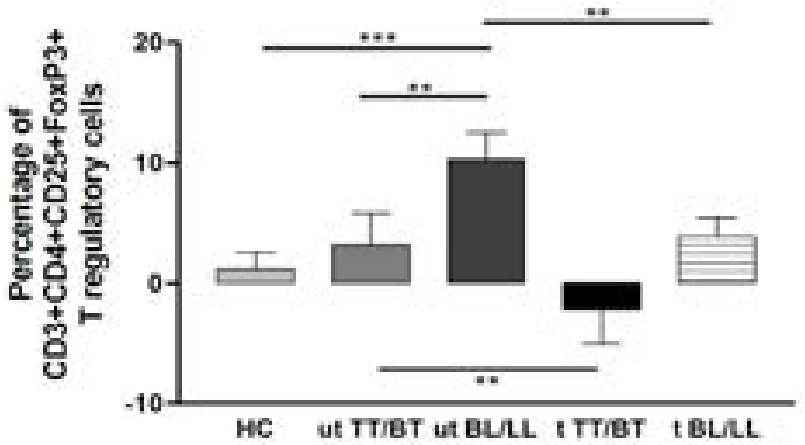

(b)

${ }^{*} \mathrm{p}<0.05,{ }^{* *} \mathrm{p}<0.001 \&$ *** $\mathrm{p}<0.0001$

Figure 3: Percentage of $\mathrm{CD} 3+\mathrm{CD} 4+\mathrm{CD} 25+\mathrm{FoxP} 3+\mathrm{T}$ regulatory cells after stimulation with $\mathrm{M}$. leprae antigens in different study subjects [HC: healthy controls ( $\mathrm{N}=10$ ), ut TT/BT: untreated fresh tuberculoid leprosy patients $(\mathrm{N}=10)$, ut $\mathrm{BL} / \mathrm{LL}$ : untreated fresh lepromatous leprosy patients ( $N=10), t \mathrm{TT} / \mathrm{BT}$ : treated tuberculoid leprosy patients $(\mathrm{N}=10)$, t BL/LL: treated lepromatous leprosy patients $(\mathrm{N}=10)]$. (a) Frequency after stimulation with whole cell sonicate. (b) Frequency after stimulation with phenolic glycolipid-1.

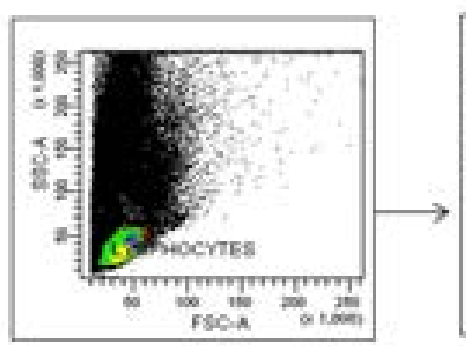

(a)

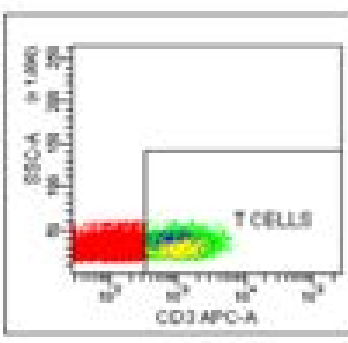

(b)

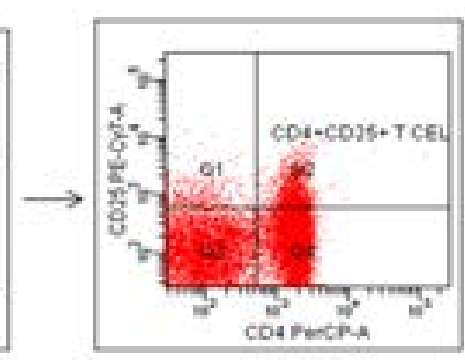

(c)

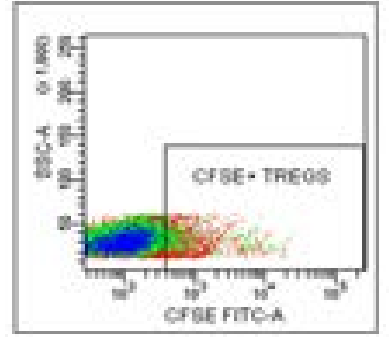

(f)

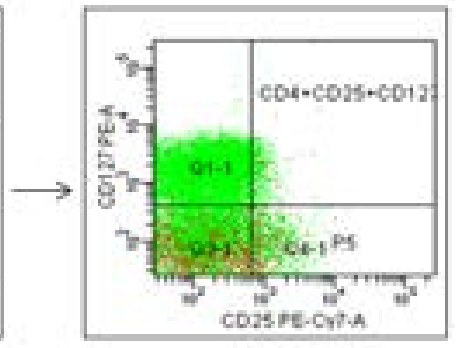

(d)

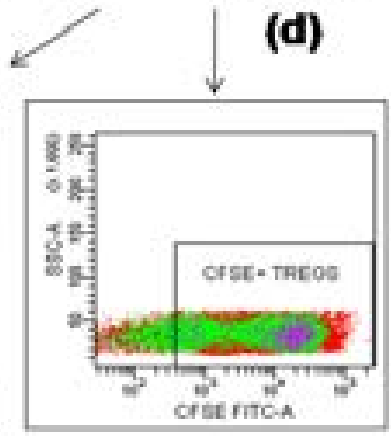

(e)

Figure 4: Representative dot plots show the gating procedure for analysis of T CD3+CD4+CD25+CD127lowCFSE+ T regulatory cells. (a) Selection of lymphocyte. (b) Selection of CD3+ cells from lymphocytes. (c) Selection of CD4+CD25+ cells from CD3+ cells. (d) Selection of CD127low cells from CD3+CD4+CD25+ cells. (e) Selection of CFSE+ cells from CD3+CD4+CD25+CD127low unstimulated cells. (f) Selection of CFSE+ cells from CD3+CD4+CD25+CD127low stimulated cells. 
Citation: Dua B, Sharma B, Chakma JK, Arora M, Bhadauria R, et al. (2016) Expansion of T regulatory cells in lepromatous leprosy is mediated by Phenolic glycolipid-1. J Med Microb Diagn 5: 226. doi:10.4172/2161-0703.1000226

Page 5 of 5

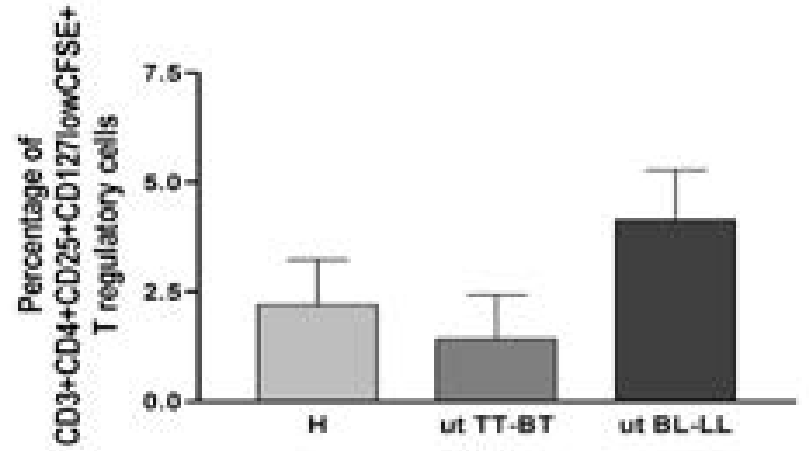

(a)
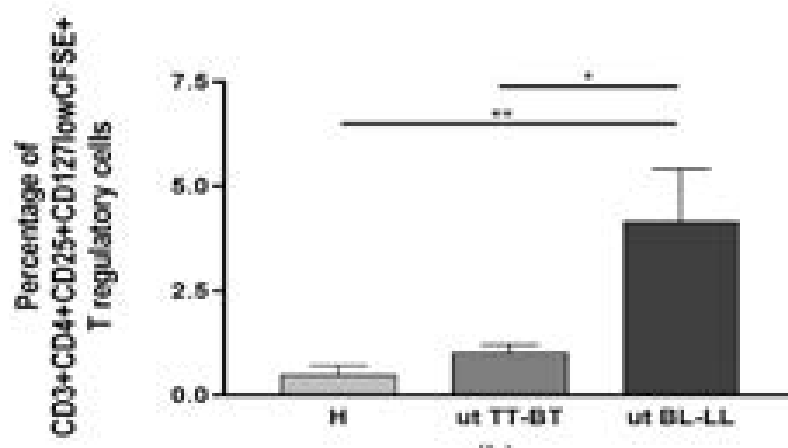

(b)

${ }^{*} \mathrm{p}<0.05,{ }^{* *} \mathrm{p}<0.001$

Figure 5: Percentage of CD3+CD4+CD25+CD127lowCFSE + T regulatory cells after stimulation with $M$. leprae antigens in different study subjects [HC: healthy controls $(\mathrm{N}=10)$, ut TT/BT: untreated fresh tuberculoid leprosy patients $(\mathrm{N}=10)$, ut $\mathrm{BL} / \mathrm{LL}$ : untreated fresh lepromatous leprosy patients $(\mathrm{N}=10)]$ (1) Frequency after stimulation with whole cell sonicate. (2) Frequency after stimulation with phenolic glycolipid-1.

of T regulatory cells in untreated patients, therefore PGL-1 may be one of the factors responsible for the increased frequency of $\mathrm{T}$ regulatory cells and thereby leading to immunosuppression in lepromatous leprosy patients. Multi drug therapy brings down the frequency of $\mathrm{T}$ regulatory cell in treated leprosy patients. These findings give lead to understanding the mechanism of PGL-1 mediated induction of T regulatory cells in future studies.

\section{Acknowledgments}

The authors acknowledge ICMR, Delhi for funding the present study. Help given by Mr. Hariram Dwivedi and Mr. Dalveer Singh, Para Medical worker, Mr. Brajendra Singh, Medical Social Worker, Mr. MM Alam and Mr. Ravi Rawat, Lab Technicians, Immunology Division, NJIL \& OMD, Agra for sample collection is also acknowledged.

\section{References}

1. Bloom BR, Global T (1983) Selective primary health case: strategies for control of disease in the developing world. Rev Infec Dis 5: 765-780.

2. Myrvang B, Global T, Ridley DS, Proland SS, Songk KK (1973) Immune responsiveness to Mycobacterium leprae and other mycobacterial antigens throughout the clinical and histological spectrum of leprosy. Clin Exp Immunol 14: $541-553$

3. Fontenot JD, Gavi MA, Rudenski AY (2003) FoxP3 programmes the development and function of CD4+ CD25+ regulatory T cells. Nat Immunol 4: 330-336.

4. Baecher AC, Brown JA, Freeman GF, Hafler DA (2001) CD4+CD25high regulatory T cells in human peripheral blood. J Immunol 167: 1245-1253.
5. Sakaguchi S (2003) Regulatory T cells: mediating compromise between host and parasite. Nat Immunol 4: 10-11.

6. Sackaguchi S (2004) Naturally arising CD4 regulatory T cells for immunologic self tolerance and negative control of immune response. Ann Rev Immunol 22 531-562.

7. Pandiyan P, Zheng L, Ishihara S, Reed J, Lenardo MJ (2007) CD4+ CD25+ Foxp3+ regulatory $\mathrm{T}$ cells induce cytokine deprivation mediated apoptosis of effector CD4+ T cells. Nat Immunol 8: 1353-1362.

8. Ghiringelli F Menard C, Terme M, Flament C, Taieb J, et al (2005) CD4+CD25+ regulatory $\mathrm{T}$ cells inhibit Natural killer cells in transforming growth factor- $\beta$ (TGF- $\beta$ ) dependent manner. J Exp Med 202: 1075-1085.

9. Garra OA, Vieira PL, Vieira P, Goldfeld AE (2004) IL-10 producing and naturally occurring CD4+ T regs: limiting collateral damage. J Clin Invest 114: 1372 1378.

10. Thronton AM, Shevach EM (1998) CD4+CD25+ immunoregulatory cells suppress $\mathrm{T}$ cell activation in in-vitro by inhibiting IL-2 production. J Exp Med 188: 287-296.

11. Mendez S, Reckling SK, Piccrillo CA, Sacs D, Belkaid Y (2004) Role of CD4+ $\mathrm{CD} 25+$ regulatory cells in reactivation of persistent Leishmania and control of concomitant immunity. J Exp Med 200: 201-210.

12. Rodrigues RR, Resende Co T, Rojar R, Tossi Z, Ditere R, et al. (2006) A role of regulatory $T$ cells in regulation of immune response during human tuberculosis. Clin Exp Immunol 144: 25-34.

13. Guyot RV, Innes JA, Hackforth S, Hinks T, Lalvani A (2006) Regulatory T cells are expanded in blood and disease site in patients with tuberculosis. Am J Resipe Crit Care Med 173: 803-810.

14. Chen X, Zhou B, Li M, Deng Q, Wu X, et al. (2007) CD4+ CD25+ Fox P3 regulatory $T$ cells suppress Mycobacterium tuberculosis immunity in patients with active diseases. Clin Exp Immunol 123: 50-59.

15. Attia EAS, Abdallah M, Saad AA, Afifi A, El Tabbakh A, et al. (2010) Circulating CD4+ CD25 high FoxP3 + T cells very in different clinical forms of leprosy. Int J Dermatol 49: 1152-1158.

16. Maria L, Pagliari C, Trindade MAB, Yamashitafuji TM, Duarte AJS, et al. (2012) Increased expression of regulatory $T$ cells and down regulatory molecules in lepromatous leprosy. Am J Trop Med 86: 878- 883.

17. Saini C, Ramesh V, Nath I (2014) Increase in TGF- $\beta$ secreting CD4+CD25+FoxP3+ T regulatory cells in anergic lepromatous leprosy patients. PLOS Neg Trop Dis 8: 1-14.

18. Mehra V, Brennan PJ, Rada E, Convit J, Bloom BR (1984) Lymphocyte suppression in leprosy induced by unique M. leprae glycolipid. Nature 308: 194-196.

19. Duppre NC, Camacho LAB, Sales AM, Illarramendi X, Nery JAC, et al. (2012) Impact of PGL-I Seropositivity on the Protective Effect of BCG Vaccination among Leprosy Contacts: A Cohort Study. PLOS Neg Trop Dis 6: e1711.

20. Boyum A (1968) Isolation of mononuclear cells and granulocytes from human blood. Scad J Clin Lab Invest 97: 77-89.

21. Han Y, Guo Q, Zhang M, Chen Z, Cao X (2009) CD69+CD4+CD25- T cells a new subset of regulatory $T$ cells, suppress $T$ cell proliferation through membrane bound TGF- $\beta 1$. J Immunol 182: 111-120.

22. Callegaro-Filho D, Shrestha N, Burdick AE, Haslett PA (2010) A potential role of complement in immune invasion by Mycobacterium leprae. J Drug Dermato 9: 1373-1382.

23. Garg A, Barner PF, Roy S, Quiroga MF, Wu S, et al. (2008) Mannose-capped lipoarabinomannan and postglandlin E2 - depentendt expansion of regulatory $T$ cells in human Mycobacterium tuberculosis infection. Eur J Immunol 38: 459-469. 